\title{
La poesía política de Carlos Germán Belli
}

\author{
The Political Poetry of Carlos Germán Belli
}

A poesia política de Carlos Germán Belli

\section{Víctor Vich}

PONTIFICIA UNIVERSIDAD CATÓLICA DEL PERÚ, PERÚ

Es docente en la Pontificia Universidad Católica del Perú y tiene un

Ph.D. de Georgetown University. Sus últimos libros publicados son

Poéticas del duelo: ensayos sobre arte, memoria y violencia en el Perú

(Instituto de Estudios Peruanos, 2015), Desculturizar la cultura: la gestión cultural como forma de acción política (Siglo XXI, 2014) y

Voces más allá de lo simbólico: ensayos sobre poesía peruana (Fondo de Cultura Económica, 2013). Correo electrónico: vvich@pucp.pe 


\section{Resumen}

Este ensayo comenta la poesía de Carlos Germán Belli, escritor decisivo en la poesía hispanoamericana actual. Se concentra en analizar un conjunto de representaciones que aluden tanto a la estructura de la sociedad como a la producción de un sujeto funcional a ella. Estudia la representación de diversos mecanismos de dominación social, pero, a la vez, subraya los espacios de resistencia. El ensayo observa cómo se trata de una poesía que ofrece intensas (y muy tensas) dinámicas de poder y liberación, de control y utopía.

Palabras clave: Poesía hispanoamericana; Carlos Germán Belli; modernidad; crítica social

\section{Abstract}

Commenting on the poetry of Carlos Germán Belli, a key writer in contemporary SpanishAmerican poetry, the present article focuses on analyzing a set of representations that allude both to the structure of society and to the production of a functional subject for that society. The article studies the representation of diverse mechanisms of social domination but, at the same time, it highlights the spaces of resistance. Finally, it observes how his poetry offers intense (and very tense) dynamics of power and liberation, control and utopia.

Keywords: Spanish-American poetry; Carlos Germán Belli; modernity; social critique

\section{Resumo}

Este ensaio comenta a poesia de Carlos Germán Belli, escritor decisivo na poesia hispanoamericana atual. Foca-se em analisar um conjunto de representações que aludem tanto à estrutura da sociedade quanto à produção de um sujeito funcional a ela. Estuda a representação de diversos mecanismos de dominação social, mas ao mesmo tempo, remarca os espaços de resistência. O ensaio observa como é uma poesia que oferece intensas (e muito tensas) dinâmicas de poder e liberação, controle e utopia.

Palavras-chave: poesia hispanoamericana; Carlos Germán Belli; modernidade; crítica social

\section{Cómo citar este artículo:}

Vich, Víctor. "La poesía política de Carlos Germán Belli". Cuadernos de Literatura 22.44 (2018): 276-287. https://doi.org/10.11144/Javeriana.cl22-44.ppcg 
"En medio de tantos vericuetos sintácticos, métricos, estróficos, esto está presente".

En la Poesía de Carlos Germán Belli, asistimos al más profundo deterioro de lo cotidiano y esta representación la dota de un alto contenido político. Se trata de una poesía que politiza la descripción misma de la cotidianidad, a la que experimenta como un lugar que no amplía las libertades del individuo y que suprime toda posibilidad de iniciativa personal. Muchos de sus poemas muestran cómo el proyecto de la modernidad no ha cumplido sus promesas y, más bien, parece haber revertido contra sí mismo. El ideario de la modernidad había sido muy claro: el capitalismo garantizaría la generación de riqueza, la tecnología reduciría buena parte del trabajo humano y el Estado sería un garante de las libertades individuales.

Nada de aquello lo observamos en algunos de los más conocidos poemas de Carlos Germán Belli: ni trabajo digno, ni calidad de vida, ni tiempo libre. Más bien, muchos de sus poemas son el testimonio de un sujeto que se ha vuelto esclavo de una maquinaria que tritura su personalidad, deteriora el lazo social y corroe el carácter. Estos poemas dan cuenta de un tipo de sociedad que sume al sujeto en la escasez económica y en la más profunda angustia existencial. Carlos Germán Belli ha escrito una poesía cuya queja es tanto un testimonio sobre su situación personal como una franca protesta sobre el lado más oscuro del capitalismo occidental.

Esta poesía utiliza una estética vieja, pero no para reconstruir un pasado idealizado, sino para dar cuenta del deterioro del presente moderno. Su lenguaje (su dicción, sus figuras, su propia sintaxis) es arcaico (o arcaizante), pero el mundo representado es de una asombrosa actualidad política. Roberto Paoli ha señalado que, en esta obra, nos enfrentamos al "choque entre la degradación humana en la sociedad contemporánea y los extintos códigos hiperliterarios que el poeta pone en actividad para comunicarla" (Paoli 42); Vargas Llosa, por su parte, la ha descrito así:

Su poesía está hecha de inconcebibles aleaciones: la métrica del Siglo de Oro y la jerga callejera de Lima; la sinrazón y el lujo del surrealismo y la sordidez de la vida de la clase media de una sociedad del tercer mundo; la nostalgia y el sueño de una existencia pletórica que se hace trizas al estrellarse diariamente con el desmentido de la experiencia y la que tercamente se rehace por obra del deseo y de la imaginación para despedazarse otra vez, el primer choque con el fatídico principio de realidad. (Vargas Llosa 209) 
En este ensayo, voy a concentrarme en algunos poemas de sus primeros libros. Me interesa analizar el malestar que la voz poética siente al constatar que el trabajo en las sociedades capitalistas no es una acción que contribuya a realizar las potencialidades humanas; sino que, por el contrario, las limita, las reprime y la sume en la desesperación personal. La categoría de "alienación” me servirá para observar cómo el trabajo aparece representado como un instrumento de dominación al interior de un sistema intensamente burocratizado que ha roto la promesa de unir trabajo y placer. Comencemos entonces con el poema titulado "Amanuense" que apareció en el libro El pie sobre el cuello (1964):

Ya descuajeringándome, ya hipando

hasta las cachas de cansado ya

inmensos montes todo el día alzando

de acá para acullá de bofes voy,

fuera cien mil palmos con mi lengua

cayéndome a pedazos tal mis padres

aunque en verdad yo por mi seso raso

$\mathrm{y}$ aun por lonjas y levas y mandones

que a la zaga me van dejando estable

ya a más hasta el gollete no poder,

al pie de mis hijuelas avergonzado

cual un pobre amanuense del Perú.

(Belli 72)

Sabemos que Belli trabajó muchos años como un funcionario público durante algunas de las más duras décadas de la historia peruana, marcadas por intensa agitación social, dictaduras militares, violencia política y, sobre todo, una permanente crisis económica que generó una gran precariedad en casi todos los sectores del país. La vida de Belli no es la de un personaje exitoso, sino la de un ciudadano común atrapado en la más dura cotidianidad peruana.

¿Qué tipo de subjetividad emerge del poema anterior? ¿Cuál es el contexto social en el que se ubica? En principio, podemos decir que ese lenguaje barroco, tan cargado de imágenes y tan denso en su sintaxis, apunta a representar una subjetividad saturada de mandatos y sumida en una vida que lo aliena y lo desubjetiviza sin piedad. En este poema, en efecto, el sujeto se encuentra en una situación límite. "Descuajeringado" es una palabra que nombra un estado de desestructuración e "hipando" 
refiere a una pulsión que se repite y que se impone una y otra vez. Sin control sobre la situación en la que ha quedado inserto, el sujeto va de "bofes" de un lado para otro y lo vemos cayéndose sobre la realidad en la que habita.

Se trata, en buena cuenta, no ya de la lucha por la sobrevivencia, sino de la representación de un poder que parecería gozar en el acto mismo de humillar al sujeto y de controlarlo a su antojo. El poema muestra cómo la subjetividad ha sido despojada de todo y se ha vuelto una pura función del poder. Me explico más: lo que a este poema le interesa representar es, sobre todo, la pérdida de agencia del sujeto bajo una situación de completa dominación social, un momento en el que la subjetividad se ha vuelto un simple efecto de una maquinaria llena de "mandones" que solo lo van alienando cada vez más.

Este tipo de desubjetivación, entendida como pérdida del sujeto sobre sí mismo (como alienación, como corrosión) es, en realidad, una franca humillación social. Por eso mismo, la alusión a las hijas resulta central, pues da cuenta del carácter dramático de un sujeto que no puede satisfacer las necesidades de quienes más quiere. En efecto, el sistema ha puesto a este sujeto en una posición en la que ya no puede cumplir sus obligaciones como padre y eso lo frustra y le genera mucha impotencia y malestar. Este es un sujeto que ha perdido autoridad y que ya no puede ser un modelo de identidad para nadie.

Por si fuera poco, el poema concluye localizando dicha situación en una realidad siempre en deterioro. En esta poesía, las alusiones al Perú son constantes y sirven para hacer más visible un conjunto de problemáticas que Belli está muy lejos de individualizar y que, más bien, son entendidas en el corazón de una modernidad muy mal constituida. El poema titulado "Papá, mamá" del libro ¡Oh Hada Cibernética! (1961-1962) es otro buen ejemplo al respecto:

Papá, mamá para que yo, Pocho y Mario sigamos todo el tiempo en el linaje humano, cuanto tiempo luchasteis vosotros a pesar de los bajos salarios del Perú, y tras de tanto tan solo me digo: "venid, muerte, para que yo abandone este linaje humano, y nunca vuelva a él, 
y de entre otros linajes escoja al fin

Una faz de risco

Una faz de olmo

Una faz de búho"

(Belli 49)

El agobio ante la vida tiene aquí una explicación histórica y un carácter hereditario y reiterativo. Nuevamente, la alusión a los lazos familiares adquiere un lugar central. En realidad, este poema se abre hacia un tipo de representación donde ya no es solo el sujeto el que se encuentra entrampado, sino que es el país entero (y, más aún, todo el "linaje humano") el que aparece incapaz de poder resolver sus problemas.

Como no parece haber posibilidades de revertir dicha situación, el sentimiento de fatalidad se hace presente. Sin un pasado que idealizar, pero tampoco sin un futuro a la vista, a la voz poética no le queda otra cosa que convocar a la muerte, pedirla intensamente, pues la vida se ha vuelto una experiencia de escasez y una imposibilidad de desarrollarse uno mismo. Notemos que la protesta se figura como algo radical. Sin dudas ni nostalgias, el poema enfatiza la necesidad de abandonar la condición humana y salir de ella de una vez por todas. Mediante una imaginería heredada del "locus amoenus" renacentista, la voz poética pide entonces transfigurarse en una montaña, en un árbol o en la sabiduría de un animal calmado y pensativo. En realidad, lo que se desea es un final, quizá la muerte. Veamos un nuevo poema, "Segregación N. ${ }^{1}$ ", que apareció en su primer libro de 1958:

\footnotetext{
Yo, mamá, mis dos hermanos

y muchos peruanitos

abrimos un hueco hondo, hondo

donde nos guarecemos

porque arriba todo tiene dueño,

todo está cerrado con llave

sellado firmemente

porque arriba todo tiene reserva:

la sombra del árbol, las flores,

los frutos, el techo, las ruedas,

el agua, los lápices,

y optamos por hundirnos

en el fondo de la tierra
} 
más abajo que nunca

lejos, muy lejos de los jefes

hoy domingo

lejos, muy lejos de los dueños,

entre las patas de los animalitos

porque arriba

hay algunos que manejan todo,

que escriben, que cantan, que bailan,

que hablan hermosamente

y nosotros rojos de vergüenza,

tan solo deseamos desaparecer

en pedacititos.

(Belli 3o)

Este poema apunta en varias direcciones. Con amargura, la voz poética señala la rígida jerarquización que existe en la sociedad y muestra los efectos de la privatización de lo público como un hecho que ha dejado excluida a buena parte de la población. En el mundo actual, todo está cerrado y todo tiene dueño, todo ha sido reservado solo para quienes tienen poder. El sujeto se encuentra en una gran crisis personal y aparece colapsando.

Los dueños, los poderosos, son los representantes de una sociedad mal constituida que posiciona a la mayoría de la población como una especie de "parte sin parte" del sistema social. Sin embargo, más allá de monopolizarlo todo, el poema muestra cómo los jefes gozan a expensas del sufrimiento de otros y este goce no es otra cosa que el ejercicio mismo de la autoridad y la voluntad de acumulación. La voz poética reconoce que ya no encuentra escapatoria posible y que solo le queda esconderse en un hueco hondo y avergonzante. En este poema, la dominación parece ser total.

Introduzcamos, sin embargo, una pregunta más radical: ¿hay resistencia en la poesía de Carlos Germán Belli? ¿En qué consiste? ¿Qué imágenes se figuran sobre ella? Una primera respuesta podría sostener que existen al menos tres estrategias de resistencia política. La primera, de carácter personal, se localiza en el cuerpo; la segunda propone que sí existe algo que podría contribuir a la liberación del trabajo; y la tercera, radicalmente política, que aboga por una acción revolucionaria. Comencemos por la primera y con el poema titulado "Ha llegado el domingo" del poemario Dentro \& fuera que se publicó en 1960: 


\begin{abstract}
Ha llegado el domingo
y procedo a desollarme como a un oso:

me desenchufo

y exprimo el sucio overol que cubre mi sangre
\end{abstract}

Caen entonces al fondo de la tina

goterones de sudor frío

pelos erizados

poros entreabiertos por el miedo

y de inmediato un verde césped reemplaza

mi antigua piel.

(Belli 39)

Aquí, el día domingo no es solo un sinónimo de descanso, sino, sobre todo, un momento de liberación del poder; es decir, un momento en el que la subjetividad y el cuerpo ingresan a un espacio situado más allá de la intensa alienación social. Ante la cosificación que el sujeto sufre por la pesada carga cotidiana, ante ese sinsentido que parece haber colonizado buena parte de su subjetividad, en este poema el acto de bañarse en una tina nombra el instante en que el sujeto puede reencontrarse consigo mismo y recuperar alguna parte del placer del que ha sido despojado por el mundo moderno.

Sin embargo, en este intento por representar una pequeña recuperación de la libertad, el poema también alude a una situación de subordinación social. Como ya lo he mencionado, en todos estos poemas el trabajo ha dejado de ser una actividad creativa para convertirse simplemente en un dispositivo donde el hombre es esclavizado. La tiranía del "overol" no solo ha llegado a aprisionar al sujeto; sino, además, a confundirse completamente con su piel, con su subjetividad misma. Así, el poema describe el trabajo, o a sus efectos, como un "sudor frío", como "pelos erizados", como algo que solo genera "miedo" y puro malestar.

Por eso, el verbo "desenchufarse" resulta tan importante. En esta poesía, lo social es siempre lo alienante y lo poderoso; así como lo natural, aquello que es fresco y liberador. Para este poema, el tipo de trabajo que la modernidad ha creado no es una actividad que permita desarrollar las potencialidades que la humanidad trae consigo, sino un lugar de alienación al que se le figura como una cárcel. De hecho, si en este poema el mundo 
social aparece como una fuerza extraña y como un poder alienante, el baño en la tina emerge como lo único propio. O, mejor aún: si lo que aliena es un poder que ha terminado por inscribirse en el propio cuerpo, esta imagen nos permite acceder a un momento en el que el cuerpo se reencuentra consigo mismo en una condición natural aludida literariamente. De hecho, la dominación cede en este poema y el sujeto puede volver a sentir placer, aunque sepa, sin embargo, que al día siguiente quedará atrapado nuevamente.

La segunda imagen de resistencia se figura en las supuestas bondades que el desarrollo de la tecnología traerá consigo. Los versos la imaginan como un elemento que podría liberar al sujeto de las pesadas cargas del trabajo cotidiano. Se trata de un tópico que ya había aparecido en la Grecia antigua, específicamente en la poesía de Antipatros, quien celebró con entusiasmo la invención del molino de agua, pues dicha máquina ayudaría a que el ser humano pueda comenzar a dedicarse a otras cosas y ya no al trabajo pesado. Muchos años antes de la gran revolución informática, Belli publicó este famoso poema en el libro titulado ;Oh Hada Cibernética! (1961-1962):

¡Oh Hada Cibernética!, ya líbranos

con tu eléctrico seso y casto antídoto, de los oficios hórridos humanos, que son como tizones infernales encendidos de tiempo inmemorial por el crudo secuaz de las hogueras; amortigua, ¡oh señora!, la presteza con que el cierzo sañudo y tan frío bate las nuevas aras, en el humo enhiestas, que ni siquiera pizca gozó alguna, de los amos no ingas privativo el ocio del amor y la sapiencia. (Belli 6o)

Escrito con un lenguaje intensamente manierista y arcaizante, este es uno de los poemas más celebrados de Carlos Germán Belli. En él, podemos notar la construcción de una estética que, por un lado, consigue unir lo más viejo con lo más nuevo y, por otro, abrir un nuevo campo de representación sobre las relaciones entre el sujeto y la máquina. Sujetado al poder de los amos, privado de su libertad y esclavo de un trabajo 
alienante, nos encontramos ante el intento por neutralizar tal condición y acceder a un espacio de mayor autonomía.

En efecto, este poema es el discurso utópico mediante el cual se imagina que la tecnología podría servir para liberar al sujeto de la prisión cotidiana. Las labores diarias son descritas como instancias hórridas, como fieros huracanes, como una fatalidad que no ha parado de acompañar la historia del hombre. En este poema, Belli puso sus esperanzas en la tecnología como una fuerza aliada que podría contribuir a liberar al sujeto (a desalienarlo) y permitirle que pueda dedicarse a otros oficios: al amor, a la sabiduría, al simple ocio. Lo cierto, sin embargo, es que cincuenta años después de haber sido escrito y ya con la informática muy desarrollada, no solo no nos hemos liberado del trabajo; sino que, por el contrario, nos hemos vuelto más esclavos del mismo. "Es discutible que todos los inventos mecánicos efectuados hasta el presente hayan aliviado la faena cotidiana de algún ser humano", dice John Stuart Mill (citado en Marx 451).

Pero quizá el problema mayor no son las máquinas en-sí-mismas, sino el sistema que las regula y las gobierna, el modelo económico en el que están inscritas. La poesía de Belli parece haberse dado cuenta de aquello y por eso, desde ahí, surge la última estrategia de resistencia. Me refiero a una opción que subraya que la agencia del sujeto debe pasar a concebirse como una voluntad política. El poema titulado " $¡$ Cuánta existencia menos...!", que también apareció en ¡Oh Hada Cibernética! (1961-1962), muestra una potente imagen de la revolución y del cambio social:

¡Cuánta existencia menos cada vez, tanto en la alondra, en el risco o en la ova, cual en mi ojo, en mi vientre o en mis pies! pues en cada linaje el deterioro ejerce su dominio por culpa de la propiedad privada, que miro y aborrezco; mas, ¿por qué decidido yo no busco de la alondra compañía, y juntamente con las verdes ovas $\mathrm{y}$ el solitario risco unirnos todos contra quien nos daña al fin en un linaje solamente?

(Belli 57) 
Esta representación insiste tercamente en lo mismo: lo social, que ha sido organizado por el poder, es aquello que distancia al sujeto de la "alondra" o del "risco" y que lo aprisiona en una situación corrosiva cada vez más lejos de aquello que tiene valor. En estas condiciones, lo social se ha vuelto un lugar alienante, de dominación y poder, donde el trabajo no realiza al hombre sino, más bien, deteriora su existencia.

De hecho, hay que notar que la voz poética parece ser muy consciente de que la alineación surge al interior de un tipo específico de sociedad; es decir, que la causa última de la alienación se halla en una forma histórica de organización social que refiere al modo de producción capitalista. Para esta poesía, lo que aliena, entonces, es la propiedad privada, base misma del sistema; pues, a razón de su lógica, la mayoría de sujetos son despojados de todo poder. "El modo de producción, y no la técnica, es el factor histórico básico", sostuvo Marcuse en un conocido ensayo (181).

En resumen, al identificar el núcleo mismo de la alienación social, al haber conseguido salir de un discurso puramente individual, este poema reconoce que la debilidad del individuo frente al sistema solo puede responderle a partir de la formación de un colectivo político que decida producir el cambio social. Con un lenguaje arcaizante, una estética barroca y un lirismo elegante, el verso anima a todos los proletarios del mundo a unirse y a luchar: los versos son claros y parecen reescribir la frase final de un famoso manifiesto del siglo XIX: "por qué decidido yo no busco / de la alondra compañía / y juntamente con las verdes ovas / y el solitario risco / unirnos todos contra quien nos daña / al fin en un linaje solamente?".

En conclusión, en la poesía de Belli asistimos a la representación del hombre ordinario que constata, con horror, el deterioro de los lazos sociales y la imposibilidad de su desarrollo integral. De hecho, una de las grandes problemáticas que esta poesía levanta es aquella sobre la imposibilidad de elegir. La de Belli, en efecto, es una poesía que constata que el proyecto de la modernidad no ha implicado una expansión de libertades ni, menos aún, una mejora en la calidad de vida. Antes bien, el tipo de trabajo que el capitalismo ha creado, siempre injusto y mal pagado, es uno que no promueve la creatividad, que no proporciona tiempo libre y que sume al sujeto en la escasez y en la pura necesidad. Obligado diariamente a trabajar en una situación alienante, los poemas nos colocan ante el crudo testimonio de una subjetividad que cada vez tiene menos agencia y a la que le es muy difícil cambiar de rumbo. 
Para concluir, si volvemos a preguntarnos por la definición de sujeto que esta poesía trae consigo, la respuesta es que se trata del lugar donde se concentra todo el poder y la dominación social. Si "el éxito de una sociedad ha de evaluarse en función de las libertades fundamentales de que disfrutan sus miembros" (Sen 35), entonces la poesía de Carlos Germán Belli emerge como un testimonio desgarrado que afirma que la sociedad contemporánea no ha cumplido ninguna de sus promesas.

\section{Obras citadas}

Belli, Carlos Germán. Los talleres del tiempo. Versos escogidos. Ed. Paul W. Borgeson Jr. Madrid: Visor, 1992. Impreso.

De Certeau, Michel. La invención de lo cotidiano. Artes del decir. Ciudad de México: Universidad Iberoamericana, 1996. Impreso.

Marcuse, Herbert. El hombre unidimensional. México: Planeta, 1985. Impreso.

Marx, Karl. El capital. Crítica de la economía política (tomo 1, volumen 3, libro primero: El proceso de producción de capital; ed. Pedro Scaron). México DF: Siglo XXI, 1988/1876. Impreso.

Paoli, Roberto. Razón de ser del neoclasicismo de Carlos Germán Belli. El pesapalabras: Carlos Germán Belli ante la crítica. Ed. Miguel Ángel Zapata. Lima: Tabla de Poesía Actual 1994. 41-53. Impreso, Sen, Amartya. Desarrollo y libertad. Bogotá: Planeta, 200o. Impreso. Vargas Llosa, Mario. "Carlos Germán Belli: una poesía para tiempos difíciles". Carlos Germán Belli. Antología personal. Lima: Concytec, 1988. Impreso. 